\title{
Three-dimensional remodelling to determine best fit for hemihamate autograft arthroplasty
}

\author{
Jessica Shih MD, Dale Podolsky MD, Paul Binhammer MD FRCSC
}

\begin{abstract}
J Shih, D Podolsky, P Binhammer. Three-dimensional remodelling to determine best fit for hemihamate autograft arthroplasty. Plast Surg 2014;22(3):191-195.
\end{abstract}

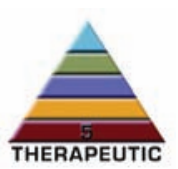

OBJECTIVE: To determine the best fit of a hamate osteochondral graft to reconstruct a palmar defect of a middle phalanx articular fracture using three-dimensional remodelling.

METHODS: The proximal middle phalanx and distal hamate articular surfaces of 10 cadaveric right hands were scanned using a three-dimensional laser scanner. A defect was marked on the middle phalanx digital image to simulate a $50 \%$ palmar lip fracture. A hemihamate autograft surgical procedure was simulated by aligning the middle phalanx and hamate digital articular surfaces. In addition to the second digit measurements, the midpoint distances of the central ridge of proximal articular surface of the middle phalanx digital image for digits 3, 4 and 5 were recorded for reference value, as well as the offset distances for the long and small finger.

RESULTS: The mean midpoint distance for the index finger was $2.96 \mathrm{~mm}$ (95\% CI $2.71 \mathrm{~mm}$ to $3.21 \mathrm{~mm}$ ). The mean angle of offset was $20.09^{\circ}(95 \%$ CI $15.54^{\circ}$ to $24.64^{\circ}$ ). The mean graft offset distance was prominent by $1.23 \mathrm{~mm}$ (95\% CI $0.57 \mathrm{~mm}$ to $1.89 \mathrm{~mm}$ ). The reference values for the third, fourth and fifth middle phalange midpoint distances were $3.26 \mathrm{~mm}$ ( $95 \%$ CI $3.09 \mathrm{~mm}$ to $3.43 \mathrm{~mm}$ ), $3.13 \mathrm{~mm}$ ( $95 \%$ CI $2.93 \mathrm{~mm}$ to $3.33 \mathrm{~mm}$ ) and $2.48 \mathrm{~mm}$ (95\% CI $2.33 \mathrm{~mm}$ to $2.63 \mathrm{~mm})$, respectively. The offset distances for digits 3 and 5 were $1.24 \mathrm{~mm}(95 \%$ CI $0.48 \mathrm{~mm}$ to $2.00 \mathrm{~mm})$ and $1.08 \mathrm{~mm}$ ( $95 \%$ CI $0.48 \mathrm{~mm}$ to $1.68 \mathrm{~mm}$ ), respectively.

CONCLUSIONS: The present study provides information about best fit for placing a hamate autograft for the hemihamate arthroplasty procedure. In this model, the hamate graft must be offset to recreate the curvature of the middle phalanx.

Key Words: 3D remodelling; Hamate arthroplasty; Middle phalanx fracture; Osteochondral graft; Phalanx reconstruction

$\mathrm{C}$ omminuted fractures of the middle phalangeal base are common and difficult to reconstruct. Early stabilization and mobilization of the damaged intra-articular joint is important to restoring proximal interphalangeal function. Many techniques have been described as treatments for middle phalanx fractures including methods of both open reduction, internal fixation and closed reduction using external fixation devices (1-6). However, hemihamate arthroplasty should be considered when $>30 \%$ of the palmar lip of the proximal middle phalanx is comminuted because it is difficult to reconstruct using other methods $(7,8)$.

Hemihamate arthroplasty involves harvesting an osteochondral graft from the dorsal hamate, which includes the articular ridge between the fourth and fifth metacarpals, to repair the comminuted palmar lip of the middle phalangeal base. The graft is fixed to the middle phalanx using screws. Published studies investigating this surgical technique have stressed the importance of recreating the curvature of the volar lip of the middle phalanx (9). Published case reports and examples of hemihamate arthroplasty tend to place the dorsal cortex of the hamate flat with the volar cortex of the middle phalanx when reconstructing the volar lip (7-9); however, this fails to recreate the curvature of the middle phalanx articular surface. Capo et al (10) used

\section{Le remodelage tridimensionnel pour déterminer la meilleure position en vue d'une arthroplastie par autogreffe de l'hémi-hamatum}

OBJECTIF : Déterminer la meilleure position du greffon ostéochondral de l'hamatum pour reconstruire une fracture articulaire de la phalange moyenne à l'aide du remodelage tridimensionnel.

MÉTHODOLOGIE : Les surfaces articulaires de la phalange moyenne proximale et de l'hamatum distal de dix mains droites cadavériques ont été numérisées au moyen d'une caméra tridimensionnelle à balayage laser. Une anomalie a été indiquée sur l'image numérique de la phalange moyenne pour simuler une fracture de $50 \%$ de la lèvre palmaire. Une chirurgie par autogreffe de l'hémi-hamatum a été simulée en faisant correspondre les surfaces articulaires de la phalange moyenne et de l'hamatum. Sur l'image numérique, les distances médianes de l'arête moyenne de la surface articulaire proximale de la phalange moyenne des doigts 3, 4 et 5 ont été enregistrées comme valeurs de référence, de même que la distance de décalage du majeur et de l'auriculaire.

RÉSULTATS : La distance médiane moyenne de l'index était de 2,96 mm (95\% IC 2,71 mm à 3,21 mm). L'angle moyen de décalage était de $20,09^{\circ}$ (95\% IC 15,54 à 24,64). La distance moyenne de décalage de la greffe saillait de 1,23 mm (95\% IC 0,57 mm à 1,89 mm). Les valeurs de référence des distances médianes de la phalange moyenne des doigts 3, 4 et 5 étaient de 3,26 mm (95\% IC 3,09 mm à 3,43 mm), 3,13 mm (95\% IC 2,93 mm à 3,33 mm) et 2,48 mm (95\% IC 2,33 mm à 2,63 mm), respectivement. La distance de décalage des doigts 3 et 5 était de $1,24 \mathrm{~mm}$ (95\% IC 0,48 mm à 2,00 mm) et de $1,08 \mathrm{~mm}(95 \%$ IC 0,48 mm à $1,68 \mathrm{~mm})$, respectivement.

CONCLUSIONS : La présente étude fournit de l'information sur la meilleure position de l'autogreffe de l'hamatum en vue d'une arthroplastie de l'hémi-hamatum. Dans ce modèle, le greffon de l'hamatum doit être décalé pour recréer la courbe de la phalange moyenne.

cadaveric reconstructions to demonstrate that to achieve biomechanical stability with no subluxation of the joint, the hamate graft must be tilted slightly to exaggerate the volar buttress so that the hamate graft is no longer flush with the middle phalanx along the volar cortex.

Clearer guidelines regarding the amount to which the hamate graft should be prominent along the volar cortex of the middle phalanx to achieve the most anatomically ideal reconstruction have yet to be described. We hypothesize that the dorsal cortex of the hamate must always be prominent compared with the volar cortex of the proximal middle phalanx. The purpose of the present study was to use threedimensional (3D) remodelling to recreate a palmar lip defect of the middle phalanx and determine the best fit of the graft to recreate the middle phalangeal base. The results will provide information for intraoperative planning.

\section{METHODS}

Following appropriate ethics approval, 10 cadaver hands were analyzed. The middle phalanx of each finger and hamate bone from each cadaver hand was dissected away from surrounding soft tissue, leaving bone and cartilage intact. Each bone was scanned using the NextEngine 3D laser scanner (NextEngine, USA), with an accuracy of $\pm 100 \mu \mathrm{m}$.

Division of Plastic $\mathcal{E}$ Reconstructive Surgery, University of Toronto, Toronto, Ontario

Correspondence: Dr Jessica Shih, Division of Plastic $\mathcal{G}$ Reconstructive Surgery, University of Toronto, 100 College Street, Room 213, Toronto,

Ontario M5G 1L5. Telephone 416-978-8534, e-mail jessica.shih@utoronto.ca 


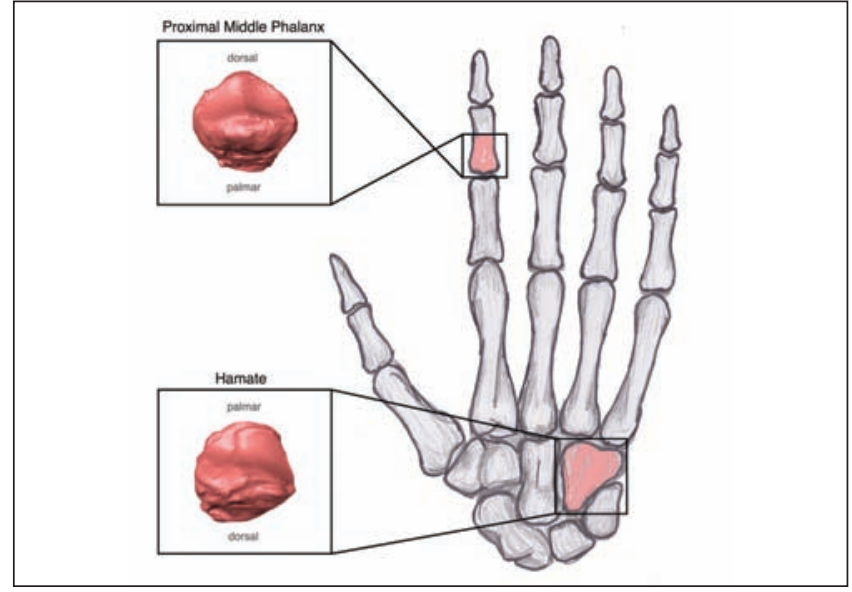

Figure 1) Software reconstruction and relative orientation of proximal middle phalanx and hamate
All scans were stored in the ASCII stereolithography format (.stl) and imported using visual imaging software (Amira version 5.3.3; Visage Imaging, USA) (11) (Figure 1). Variables were created to be able to describe the relationship between the middle phalanx and the hamate when aligned. These variables were midpoint distance, angle of offset and graft offset distance.

The visual imaging software (Amira version 5.3.3) was used to landmark and align the middle phalanx of the index finger and hamate of the same cadaver hand for all 10 subjects. The landmarking is described as follows and visually represented in Figure 2. The middle phalangeal base of the second digit and carpometacarpal joint articular surface of the hamate were first oriented with the palmar surface on the middle phalanx and the corresponding dorsal aspect of the hamate facing inferiorly. The Gaussian curvature is an intrinsic measure of curvature and provides values to describe the extent of curvature at any given point on a surface. The maximal positive and negative Gaussian curvatures of the articular surfaces were mapped to identify local peaks and troughs along the articular ridges. Landmarks A and B were pinpointed according to the depressions on the palmar ridge of

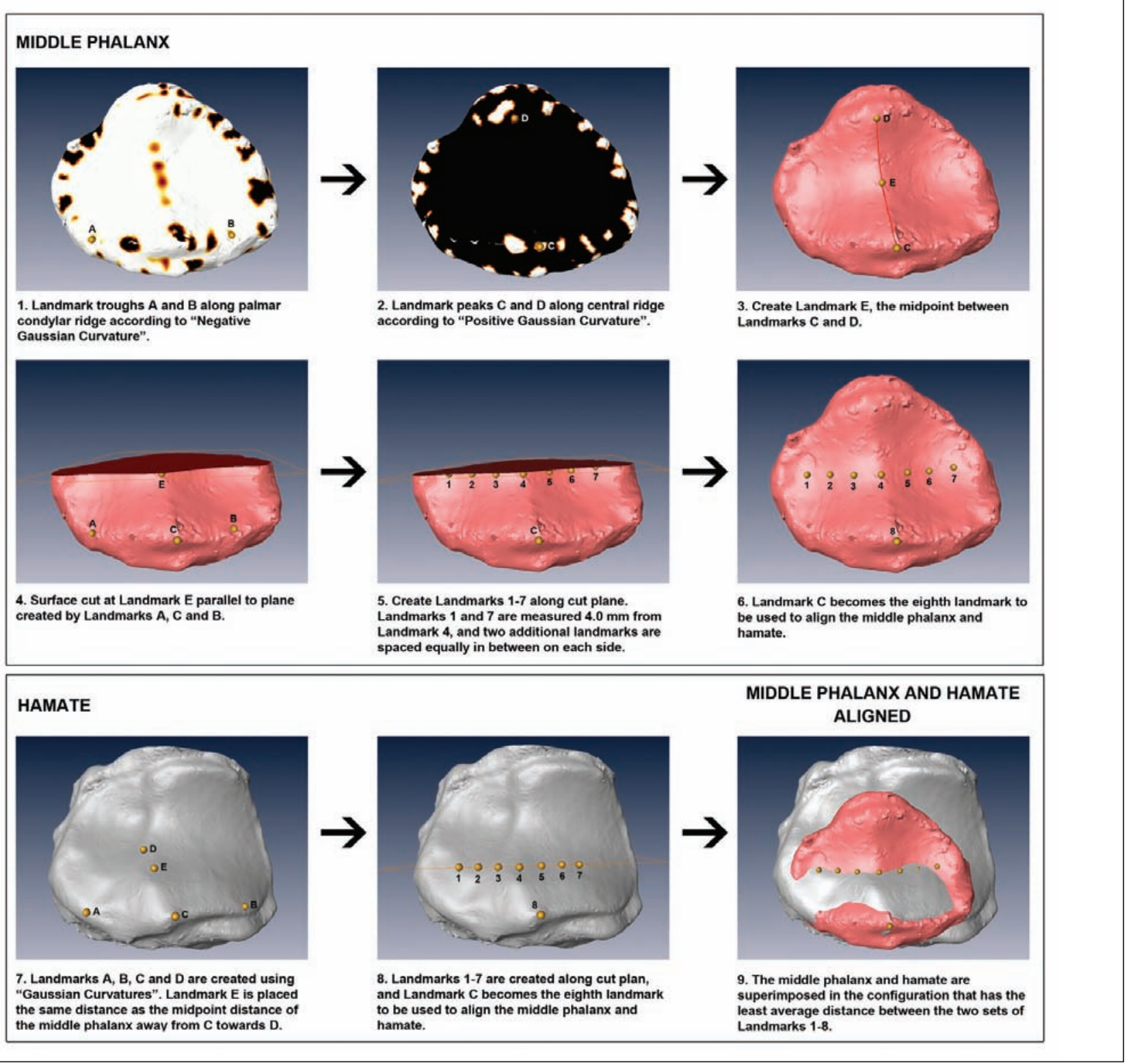

Figure 2) Method of landmarking and aligning the second digit middle phalanx and corresponding hamate of a cadaver right hand 


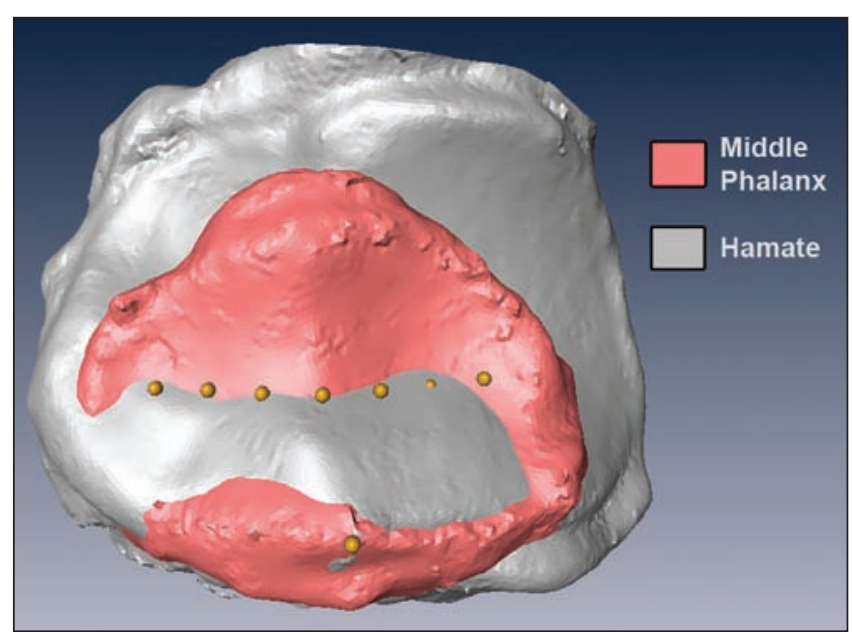

Figure 3) Alignment of second digit middle phalanx and hamate using landmarks
TABLE 1

Results for second digit middle phalanx

\begin{tabular}{lcccc}
\hline Specimen & Sex & $\begin{array}{c}\text { Midpoint } \\
\text { distance (A), mm }\end{array}$ & $\begin{array}{c}\text { Angle of } \\
\text { offset (B), }{ }^{\circ}\end{array}$ & $\begin{array}{c}\text { Graft offset } \\
\text { distance (C), } \\
\text { mm }\end{array}$ \\
\hline 1 & Female & 3.27 & 15.8 & 1.12 \\
2 & Female & 3.14 & 13.8 & 1.67 \\
3 & Male & 2.63 & 10.0 & 0.52 \\
4 & Female & 2.37 & 11.0 & 0.43 \\
5 & Female & 2.42 & 20.8 & 0.66 \\
6 & Male & 3.72 & 22.8 & 2.56 \\
7 & Male & 3.08 & 25.5 & 3.49 \\
8 & Male & 2.96 & 22.9 & 0.00 \\
9 & Male & 3.17 & 33.2 & 1.07 \\
10 & Male & 2.83 & 25.1 & 0.77 \\
Mean (95\% Cl) & & 2.96 & 20.09 & 1.23 \\
& & $(2.71-3.21)$ & $(15.54-24.64)$ & $(0.57-1.89)$ \\
\hline
\end{tabular}

Each pair of second digit middle phalanx is presented

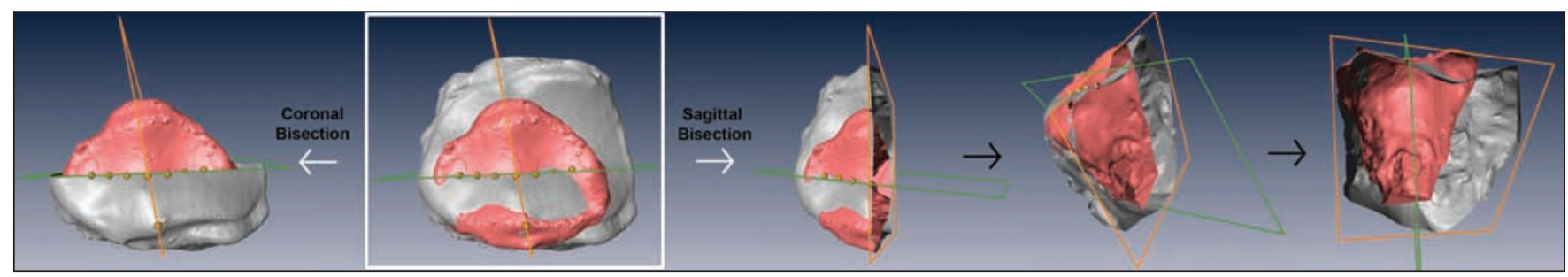

Figure 4) Coronal bisection (green plane) to reconstruct a 50\% middle phalanx palmar lip defect using a hamate graft. Sagittal bisection (orange plane) of aligned specimens to analyze best fit of the hamate graft relative to the middle phalanx

the specimen. Landmarks $\mathrm{C}$ and $\mathrm{D}$ are then pinpointed according to the peaks on the central ridge separating the radial and ulnar sides, and landmark $\mathrm{E}$ is recorded as the midpoint between $\mathrm{C}$ and $\mathrm{D}$. Therefore, the midpoint distance represents one-half of the dorsal to palmar articular surface of the middle phalanx base. The midpoint (E) at 50\% of the palmar lip landmarks represents a typical indication to consider hemihamate arthroplasty $(7,8)$. Within the software program, the specimen was then digitally cut at the midpoint distance in the coronal plane parallel to the palmar ridge, represented by landmarks A, C and B. Landmarks 1 and 7 were placed $4.0 \mathrm{~mm}$ along the plane from landmark E, and a total of seven landmarks were placed along the cut plane centred on landmark E, totalling $8.0 \mathrm{~mm}$ in width. This coronal bisection simulates the articular surface interface where the hamate graft replacing the fractured portion of the middle phalanx would meet the stable portion of the middle phalanx. The same methods were used to landmark the hamate specimen to represent the same surface area required of a hamate graft to reconstruct a $50 \%$ palmar lip middle phalanx defect. The seven landmarks plus landmark $\mathrm{C}$ on each middle phalanx base and hamate were used to mathematically align the specimens in the configuration that had the least average distance between all landmarks (Figure 3).

\section{Analysis of aligned specimens}

A sagittal bisection was made of the aligned specimens along the central ridge to view the position of the hamate relative to the middle phalanx (Figure 4). An analysis of the differences between the two surface tracings was made to provide guidance to surgeons about placement of the hamate relative to the middle phalanx for best fit (Figure 5). In addition to recording midpoint distance (represented as A), three additional variables were measured from this viewpoint that would quantitatively describe how the hamate should ideally be offset from the middle phalanx in the position of best fit as determined by the above method. The angle of offset (B) is the angle between the dorsal surface of the hamate and the palmar surface of the middle

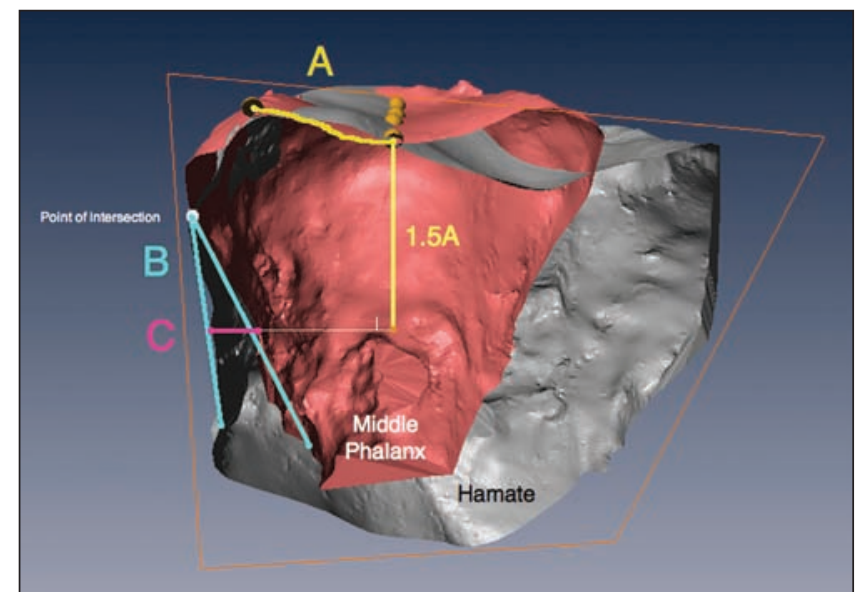

Figure 5) Sagittal view of analysis for Specimen 1. A midpoint distance. B Angle of offset. C Graft offset distance

phalanx. This angle specifies the degree to which the dorsal surface of the hamate should be offset from the palmar surface of the middle phalanx to achieve proper alignment of the two articular surfaces represented by the central ridges of both specimens. The graft offset distance $(\mathrm{C})$ is the distance between the dorsal surface of the hamate and the palmar surface of the middle phalanx at a length of 1.5 times the midpoint distance from the midpoint. This distance provides the surgeon with a more attainable intraoperative goal in determining how far to offset the graft. A length of 1.5 times the midpoint distance was chosen to provide enough length for a reasonable graft to allow fixation and manipulation and, at the same time, provide a consistent point at which to measure the graft offset distance relative to the size of each specimen. The mean and $95 \% \mathrm{CI}$ of these variables were calculated. 
TABLE 2

Middle phalanx reference values

\begin{tabular}{|c|c|c|c|c|c|c|}
\hline \multirow[b]{2}{*}{ Specimen } & \multicolumn{4}{|c|}{ Midpoint distance, $\mathrm{mm}$} & \multicolumn{2}{|c|}{ Offset distance, $\mathrm{mm}$} \\
\hline & Second digit & Third digit & Fourth digit & Fifth digit & Third digit & Fifth digit \\
\hline 1 & 3.27 & 3.10 & 3.27 & 2.56 & 0.43 & 0.29 \\
\hline 2 & 3.14 & 2.99 & 2.93 & 2.06 & -0.28 & 0.90 \\
\hline 3 & 2.63 & 2.94 & 2.81 & 2.34 & 0.96 & 0.52 \\
\hline 4 & 2.37 & 3.09 & 2.64 & 2.06 & 1.48 & 1.88 \\
\hline 5 & 2.42 & 3.17 & 3.24 & 2.78 & -0.15 & -0.74 \\
\hline 6 & 3.72 & 3.68 & 3.73 & 2.53 & 2.05 & 0.66 \\
\hline 7 & 3.08 & 3.57 & 3.21 & 2.63 & 3.90 & 2.62 \\
\hline 8 & 2.96 & 3.49 & 3.12 & 2.55 & 0.65 & 1.24 \\
\hline 9 & 3.17 & 3.12 & 2.92 & 2.60 & 1.45 & 2.04 \\
\hline 10 & 2.83 & 3.50 & 3.47 & 2.68 & 1.90 & 1.43 \\
\hline Mean $(95 \% \mathrm{Cl})$ & $2.96(2.71-3.21)$ & 3.26 (3.09-3.43) & 3.13 (2.93-3.33) & $2.48(2.33-2.63)$ & $1.24(0.48-2.00)$ & $1.08(0.48-1.68)$ \\
\hline
\end{tabular}

Reference values for third, fourth and fifth digit middle phalanx compared with the second digit middle phalanx and offset distances for the third and fifth digit

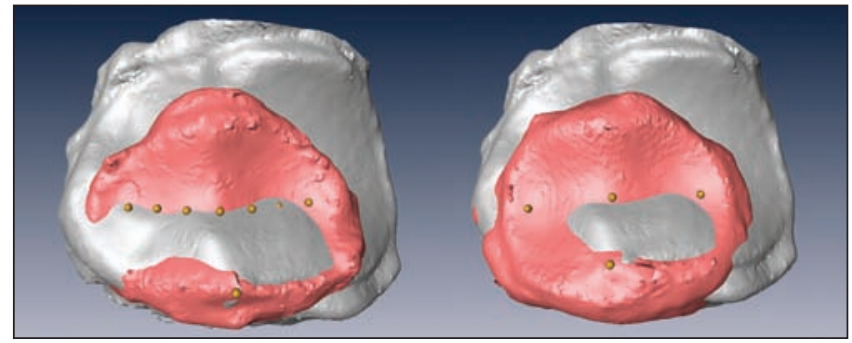

Figure 6) Simplified landmarking methods for measuring offset distances of the index finger (left side) compared with the long (right side) and small finger

Reference values of remaining digits

The midpoint distance (halfway between the palmar and dorsal peaks on the central ridge) for the third, fourth and fifth middle phalanges were measured as reference values.

\section{Statistical analysis}

The mean and 95\% CI for all measurements were calculated and reported. Hypothesis testing was performed for graft offset distance using a two-tailed $t$ test of a single mean with an unknown population SD; $P<0.05$ was considered to be statistically significant.

\section{RESULTS}

The specimens used in the present study included the right hands of four female and six male cadaver hands with a mean age of 76.3 years (range 55 to 91 years). The mean midpoint distance was $2.96 \mathrm{~mm}$ ( $95 \%$ CI $2.71 \mathrm{~mm}$ to $3.21 \mathrm{~mm}$ ) (Table 1). The mean angle of offset was $20.09^{\circ}\left(95 \% \mathrm{CI} 15.54^{\circ}\right.$ to $\left.24.64^{\circ}\right)$. The mean graft offset distance was $1.23 \mathrm{~mm}$ (95\% CI $0.57 \mathrm{~mm}$ to $1.89 \mathrm{~mm})$.

The null hypothesis - that the graft offset distance between the 2 nd digit proximal middle phalanx and hamate is equal to 0 using both methods - was rejected $(\mathrm{P}<0.01)$, which showed that the graft offset distance is not equal to 0 and is a positive value.

The reference values for the third, fourth and fifth middle phalanges midpoint distances were $3.26 \mathrm{~mm}$ ( $95 \%$ CI $3.09 \mathrm{~mm}$ to $3.43 \mathrm{~mm}$ ), $3.13 \mathrm{~mm}$ (95\% CI $2.93 \mathrm{~mm}$ to $3.33 \mathrm{~mm}$ ) and $2.48 \mathrm{~mm}$ (95\% CI $2.33 \mathrm{~mm}$ to $2.63 \mathrm{~mm}$ ), respectively, compared with the second middle phalanx midpoint distance $(2.96 \mathrm{~mm})$. The offset distances of the largest and smallest fingers (third and fifth, respectively) were $1.24 \mathrm{~mm}$ (95\% CI $(0.48 \mathrm{~mm}$ to $2.00 \mathrm{~mm})$ and $1.08 \mathrm{~mm}(95 \%$ CI $0.48 \mathrm{~mm}$ to $1.68 \mathrm{~mm})$ (Table 2).

\section{DISCUSSION}

Using hemihamate autograft arthroplasty to reconstruct comminuted middle phalangeal base fractures has been shown to have good stability and minimal donor site morbidity $(7,8,10,12)$. Currently, surgeons performing this procedure must estimate to the best of their ability the size and shape of the hamate autograft to fit the portion of the middle phalanx that has been comminuted. The present study provides information about best fit for this procedure using $3 \mathrm{D}$ remodelling. The angles are not meant to represent practical intraoperative tools; however, the graft offset distance is important. Given that the measurements in the present study were primarily assessing the second digit middle phalanx, the offset distances for the largest middle phalanx articular surface, the long finger, and the smallest, the small finger were also calculated. The methods were simplified by using four points to landmark (Figure 6). Similar results to the index finger $(1.23 \mathrm{~mm})$ were found with the offset distance for the long finger $(1.24 \mathrm{~mm})$, whereas the small finger $(1.08 \mathrm{~mm})$ had a shorter offset distance. The offset distance measurements are of particular value to surgeons because these results can be easily translated into surgical situations. The distance the graft needs to be offset for all digits was consistently $>1 \mathrm{~mm}$. By fitting the hamate according to these parameters, a surgeon can ensure that the volar lip geometry of the middle phalanx base is reconstructed accurately.

One limitation of the present study was that only one type of defect could be addressed, an average $50 \%$ comminuted defect of the middle phalanx palmar lip, when in fact proximal interphalangeal fractures occur in many depths and variations. With defects $>50 \%$ of the articular surface, the middle phalanx starts to curve up and away from the hamate, which has a larger diameter of curvature (Figure 5). Thus, defects of the middle phalanx $>50 \%$ are more problematic when using the hamate in recreating the same anterior-posterior curvature and obtaining the volar lip buttress. Therefore, one must keep this in mind when applying the results to different contexts.

The small sample size also makes it difficult to generalize and apply these findings to any given patient; however, a consistent finding was the positive offset. Another limitation was the potential for interuser differences in landmarking specimens due to natural variations in their shape. The methods used to landmark are meant to increase objectivity in aligning the specimens; however, subjectivity does exist when interpreting where to place angles when there is not a clear-cut and straight path visible to place each vector. Thus, there may be interuser variability in determining the angle of offset. The midpoint distances and offset distances are more objective measures according to the landmarking methods used.

Despite these limitations, 3D remodelling enabled visualization of the middle phalanx and hamate superimposed on one another to best 
reconstruct a hamate autograft. Once aligned, the articular surfaces of the bones are similar in curvature and shape, validating that a hamate autograft is a good graft choice to reconstruct unstable, comminuted middle phalangeal base fractures (6).

\section{REFERENCES}

1. Hynes MC, Giddins GE. Dynamic external fixation for pilon fractures of the interphalangeal joints. J Hand Surg 2001;26B:122-4.

2. Nam SM, Park ES, Shin H, Jung SG, Kim YB. Interphalangeal traction for comminuted fractures of middle phalanx fingers: Case report. J Hand Surg 2010;35A:1282-5.

3. Allison DM. Fractures of the base of the middle phalanx treated by a dynamic external fixation device. J Hand Surg 1996;21B:305-10.

4. Eaton RG, Malerich MM. Volar plate arthroplasty of the proximal interphalangeal joint: A review of ten years' experience. J Hand Surg 1980;5A:260-8

5. Seno N, Hashizume H, Inoue H, Imatani J, Morito Y. Fractures of the base of the middle phalanx of the finger: Classification, management and long-term results. J Bone Joint Surg 1997;79B:758-63.

6. Williams RM, Hastings $\mathrm{H}$, Kiefhaber TR. PIP fracture/dislocation treatment technique: Use of a hemi-hamate resurfacing arthroplasty. Techniques Hand Upper Extremity Surg 2002;6:185-92.

7. Calfee RP, Kiefhaber TR, Sommerkamp TG, Stern PJ. Hemi-hamate arthroplasty provides functional reconstruction of acute and chronic proximal interphalangeal fracture dislocations. J Hand Surg 2009;34:1232-41.
ACKNOWLEDGEMENTS: The authors thank James Mainprize and Vaibhav Patel of Sunnybrook Health Sciences Centre for their help understanding and applying the different capabilities of computer software programs. They also thank Catherine McMillan of Sunnybrook Health Sciences Centre for her assistance in reviewing the manuscript.

8. Williams RM, Kiefhaber TR, Sommerkamp TG, Stern PJ. Treatment of unstable dorsal proximal interphalangeal fracture/ dislocations using a hemi-hamate autograft. J Hand Surg 2003;28A:856-65.

9. McAuliffe JA. Hemi-hamate autograft for the treatment of unstable dorsal fracture dislocation of the proximal interphalangeal joint. J Hand Surg 2009;34:1890-4.

10. Capo J, Hastings H, Choung E, Kinchelow T, Rossy W, Steinberg B. Hemicondylar hamate replacement arthroplasty for proximal interphalangeal joint fracture dislocations: An assessment of graft suitability. J Hand Surg 2008;33:733-9.

11. Podolsky D, Mainprize J, McMillan C, Binhammer P. Comparison of third toe joint cartilage thickness to that of the finger proximal interphalangeal (PIP) joint to determine suitability for transplantation in PIP joint reconstruction. J Hand Surg 2011;36;1950-8.

12. Afendras G, Abramo A, Mrkonjic A, Geijer M, Kopylov P, Tagil M. Hemi-hamate osteochondral transplantation in proximal interphalangeal dorsal fracture dislocations: A minimum 4 year follow-up in eight patients. J Hand Surg 2010;35E:627-31. 